\title{
IDENTIFYING AND MAPPING SALT-AFFECTED LANDS IN HAMBANTOTA DISTRICT, SRI LANKA: AN INTEGRATED GIS AND REMOTE SENSING APPROACH
}

\section{Chandana Gunasena and S Subasinghe. \\ Faculty of Agriculture, \\ University of Ruhuna.}

Since available lands in Sri Lanka is decreasing every year mainly due to degradation of lands, it is very important to restore these lands for useful agricultural production. In this regard, identification of salt-affected lands and differentiates into salinity levels would help to take necessary actions to restore these lands.

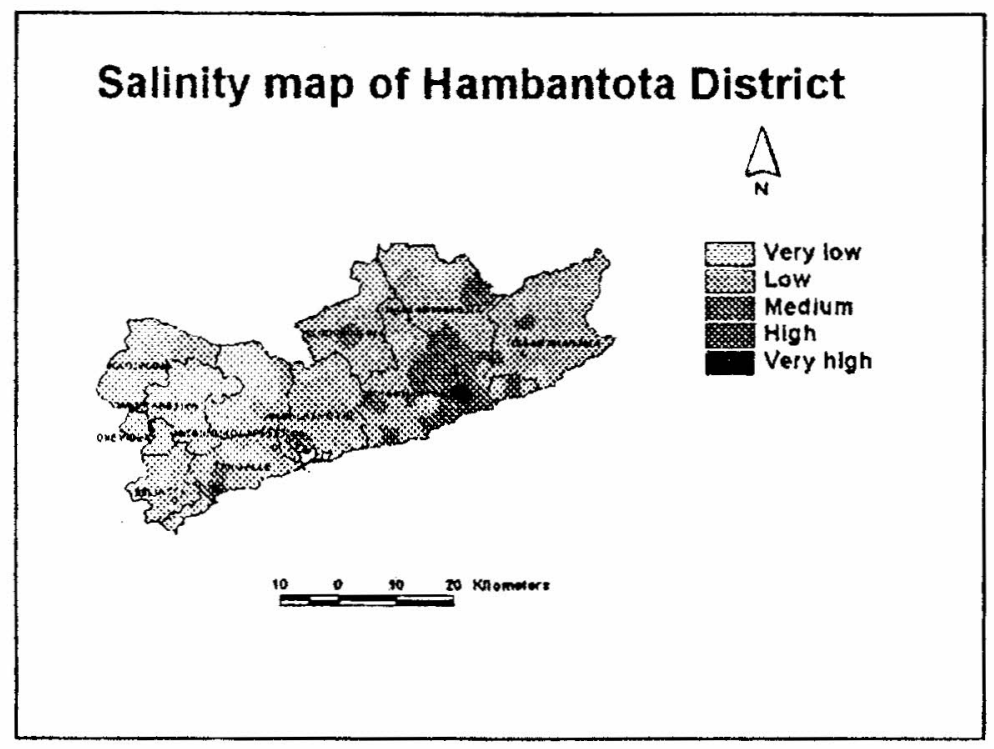

An extensive soil survey was conducted throughout the Hambantota district in order to identify the salt-affected lands in the district. The sampling was done at different depths (i.e. $0-10 \mathrm{~cm}, 10-20 \mathrm{~cm}, 20-30 \mathrm{~cm}, 30-40 \mathrm{~cm}$ and $40-50 \mathrm{~cm}$ ) by using a manual soil auger. The distance between sampling sites was approximately $3 \mathrm{~km}$. The exact position of Forestry and Environmental Science, University of Sri Jayewardenepura, Sri Lanka 
sampling points in latitude and longitude was identified by GPS (Global Positioning

System). A total number of 100 points and 400 samples were collected. Topographic maps of survey of Sri Lanka used in the study were Timbolketiya (82), Kataragama(83), Yala(84), Hambantota(88) and Tissamaharama(89) of scale 1:50,000. Digital thematic maps of same map sheets and Scale of 1:25000 digital maps were also been used.

The samples were taken to the laboratory of the Department of Crop Science, Faculty of Agrialture, University of Ruhuna, where $\mathrm{EC}$ and $\mathrm{pH}$ measurements were taken using the EC meter and the pH meter. All the locational data taken using GPS system, entered into a database. $\mathrm{EC}$ and $\mathrm{pH}$ data also been entered to the database. Using ArcView software, a point map was generated using all the locational data including $\mathrm{EC}$ and $\mathrm{pH}$ values as attribetes. By applying interpolating techniques, salinity maps were produced.

Proceedings of the Ninth Annual Forestry and Environment Symposium 2003 of the Department of Forestry and Environmental Science, University of Sri Jayewardenepura. Sri Lanka 